NBER WORKING PAPER SERIES

\title{
IRREVERSIBLE INVESTMENT, REAL OPTIONS, AND COMPETITION: EVIDENCE FROM REAL ESTATE DEVELOPMENT
}

\author{
Laarni Bulan \\ Christopher Mayer \\ C. Tsuriel Somerville \\ Working Paper 12486 \\ http://www.nber.org/papers/w12486 \\ NATIONAL BUREAU OF ECONOMIC RESEARCH \\ 1050 Massachusetts Avenue \\ Cambridge, MA 02138 \\ August 2006
}

The authors wish to thank Andy Abel, John Donaldson, Larry Glosten, Joe Gyourko, Charlie Himmelberg, Glenn Hubbard, Ken Kuttner, Robert McDonald, Bob Shiller, Todd Sinai, Nick Souleles, Will Strange, and Tan Wang for helpful comments. Special thanks are due to Zhan Binghui for research assistance. The data are the result of assistance and cooperation from Stan Hamilton and the offices of the BC, Land Title Office, Registrar of Corporations, and Superintendent of Real Estate. Financial support for this research was received from the Social Science and Humanities Research Council of Canada, the Real Estate Foundation of British Columbia, and the Zell/Lurie Real Estate Center at Wharton. Previous versions of this paper circulated under the title, "Should I Build or Should I Wait Now? Idiosyncratic Risk, Competition and Real Options in Real Estate Investment." All errors are the responsibility of the authors. The views expressed herein are those of the author(s) and do not necessarily reflect the views of the National Bureau of Economic Research.

(C2006 by Laarni Bulan, Christopher Mayer and C. Tsuriel Somerville. All rights reserved. Short sections of text, not to exceed two paragraphs, may be quoted without explicit permission provided that full credit, including () notice, is given to the source. 
Irreversible Investment, Real Options, and Competition: Evidence from Real Estate

Development

Laarni Bulan, Christopher Mayer and C. Tsuriel Somerville

NBER Working Paper No. 12486

August 2006

JEL No. D4, D52, E23, R3

\begin{abstract}
$\underline{\text { ABSTRACT }}$
We examine the extent to which uncertainty delays investment and the effect of competition on this relationship using a sample of 1,214 condominium developments in Vancouver, Canada built from 1979-1998. We find that increases in both idiosyncratic and systematic risk lead developers to delay new real estate investments. Empirically, a one-standard deviation increase in the return volatility reduces the probability of investment by 13 percent, equivalent to a 9 percent decline in real prices. Increases in the number of potential competitors located near a project negate the negative relationship between idiosyncratic risk and development. These results support models in which competition erodes option values and provide clear evidence for the real options framework over alternatives such as simple risk aversion.
\end{abstract}

\author{
Laarni Bulan \\ Brandeis University \\ International Business School \\ 415 South Street MS 021 \\ Waltham, MA 02454 \\ lbulan@brandeis.edu \\ Christopher Mayer \\ Columbia Business School \\ 3022 Broadway, Uris Hall \#808 \\ New York, NY 10025 \\ and NBER \\ cm310@columbia.edu \\ C. Tsuriel Somerville \\ Sauder School of Business \\ 2053 Main Mall \\ Vancouver, BC V6T 1 Z2 \\ CANADA \\ tsur.somerville@sauder.ubc.ca
}




\section{INTRODUCTION}

Over the last two decades, the application of financial option theory to investment in real assets has altered the way that researchers model investment. ${ }^{1}$ Under the real options approach, firms should apply a higher user cost to new investments in irreversible assets when returns are stochastic, reflecting the option to delay that is lost when investment occurs. The effects can be quite large. For example, Dixit and Pindyck (1994) use simulations to show that the optimal hurdle price triggering new irreversible investment can be two to three times as large as the trigger value when investments are reversible. Yet others argue that competition erodes option values and limits the empirical relevance of the real options framework for many industries. Empirical support for the real options model has suffered from the absence of a clean test to differentiate between real options and more traditional discounted cash flow (DCF) models of investment in which the discount rate depends on risk.

In this paper, we address these issues by examining the relationship between uncertainty, competition, and irreversible investment using unique data on 1,214 individual real estate projects (condominium or strata buildings) built in Vancouver, Canada between 1979 and 1998. In looking at real estate, we examine an asset class that represents a large component of national investment and wealth and a sector that exhibits great cyclical volatility in investment.

Some theoretical papers have argued that real options models have limited power to

\footnotetext{
${ }^{1}$ Reviews of the theoretical literature include Dixit and Pindyck (1994), Trigeorgis (1996), and Brennan and Trigeorgis (2000). Among the seminal papers in this areas are Abel (1983), Bernanke (1983), Brennan and Schwartz (1985), McDonald and Siegel (1986), Majd and Pindyck (1987), Pindyck (1988), Dixit (1989), and Abel, Dixit, Eberly, and Pindyck (1996).
} 
predict investment in competitive markets. Caballero (1991) suggests that imperfect competition is vital to predicting a negative relationship between uncertainty and investment. For example, competition might mitigate the value of a real option through the threat of preemption as in Grenadier (2002). Trigeorgis (1996) associates increased competition with a higher dividend yield from the underlying asset. When the dividend is high enough, it can induce early exercise by reducing the value of the option to wait. In a similar vein, Kulatilaka and Perotti (1998) argue that firms with a strategic advantage (market power) are in a better position to gain greater growth opportunities when uncertainty is higher. This induces more investment in growth options for this type of firm while companies that do not have a strategic advantage will be discouraged from investing.

In response to these critiques, others argue that with the addition of a few realistic assumptions, the value of the option to wait is preserved even with perfect competition. For example, Novy-Marx (2005) shows that competition does not diminish the value of an option to develop in the case of differentiated products such as real estate where locations are never perfect substitutes for each other and sites have varying opportunity costs of development due to differences in the pre-existing use of a site. Leahy (1993) and Dixit and Pindyck (1994) also contend that perfect competition does not necessarily reduce the value of waiting.

Existing empirical research has been mixed as to the existence of a negative relationship between volatility and investment, although recent work has tended to be more supportive (Downing and Wallace (2001) and Moel and Tufano (2002)). Nonetheless, real options models are not the only models in which one would expect a negative correlation between uncertainty and investment, an issue that is often not discussed in empirical real options research. In fact, if increases in volatility are driven by a greater exposure to non-diversifiable risk, most 
neoclassical models (such as the familiar capital asset pricing model--CAPM) would predict that greater uncertainty would lead to lower investment through an increase in the investor's required rate of return. In the case of incomplete markets, even increases in idiosyncratic risk will cause risk-averse investors to reduce investment if they cannot adequately hedge this type of risk. This latter condition is especially likely in the context of real estate, where many investors and developers are small and hold portfolios that are concentrated in a particular local market where they hold great expertise, but where there are no existing methods to hedge local market risk. Our findings described below address both of these issues.

We find clear support for the negative relationship between idiosyncratic uncertainty and investment that is a crucial prediction of the real options model. To separate the impact of the alternative models, real options and the CAPM, we decompose the volatility of condominium returns into idiosyncratic and market risk components. As predicted by the real options model, exposure to idiosyncratic risk reduces investment. However, consistent with the CAPM, exposure to market volatility also delays investment to nearly the same extent. A one standard deviation increase in idiosyncratic volatility reduces the probability of development by 13 percent, about the same predicted impact on new investment as a 9 percent decrease in real prices. A similar one standard deviation increase in market volatility is equivalent to a 7 percent fall in real prices.

Addressing the debate about how market structure impacts option exercise, we show that competition, measured by the number of potential competitors for a project, reduces the impact of condo return volatility on new investment. Empirically, competition has little direct effect on investment. Instead, competition only matters when interacted with volatility. We show that volatility has a smaller impact on option exercise for developments surrounded by a larger 
number of potential competitors. In fact, for the 5 percent of all units facing the greatest number of potential competitors, idiosyncratic volatility has virtually no effect on the timing of investment. These findings provide unambiguous support for the models of Caballero, Trigeorgis and Grenadier, which show that competition can erode the value of the option to delay irreversible investment.

Finally, the finding that competition only impacts investment indirectly through its correlation with uncertainty provides support for the real options model even in the presence of risk averse owners and incomplete markets. While risk averse owners without hedging opportunities will reduce investment in response to greater idiosyncratic volatility, only a real options model has the additional prediction that option value diminishes with competition.

The relationship between competition and real option exercise may help explain the strong pro-cyclical correlation between investment and output. Macro economists have often puzzled over the high volatility of investment relative to output, documented over long periods of time and across many countries (Basu and Taylor (1999)). Variation in competition over the cycle could provide at least one explanation for the excess volatility of investment. Rotemberg and Saloner (1986) and Rotemberg and Woodford (1991, 1992) argue that tacit collusion is difficult to sustain in booms, relative to busts. Our findings suggest that variation in competition can impact investment. Firms might optimally further delay investment in busts when product markets are less competitive, but undertake equivalent investments in booms when they face greater competition. This higher volatility for investment is consistent with the macro evidence.

The remainder of the paper is structured as follows. Section II provides a review of related work and a discussion of how this paper fits in with the empirical real options literature. In Section III, we present the empirical specification along with a summary of its theoretical 
suppport. We also discuss the impact of various assumptions on the specification with respect to the completeness of capital markets and the unique properties of the real estate market. We present a more detailed discussion of the data in Section IV. The empirical results are presented in Section V, and in Section VI we conclude.

\section{EXISTING LITERATURE}

Real options theory has been applied to describe a broad range of investments and industries. ${ }^{2}$ Macroeconomic aggregate studies by Pindyck and Solimano (1993) and Caballero and Pindyck (1996) find a negative relationship between aggregate investment and uncertainty, where uncertainty is measured as the variance in the maximum observed marginal revenue product of capital. Other papers (Holland, Ott, and Riddough (2000), Sivitanidou and Sivitanides (2000), and Sing and Patel (2001)) examine this relationship specifically for real estate development, and usually, but not always, finding a negative relationship between uncertainty and development. Leahy and Whited (1996) and Bulan (2005) also obtain mixed results when examining the effect of a firm's daily stock return volatility on the firm-level investment-capital stock ratio for a panel of manufacturing firms. However, real options models apply to individual investment projects and predict that trigger prices are non-linear, so aggregate investment studies may obscure these relationships.

Studies that use project level investment data have the advantage of being able to relate individual investment decisions to direct measures of demand uncertainty such as output price

\footnotetext{
${ }^{2}$ Applications include investments in natural resources extraction (Brennan and Schwartz 1985; Paddock, Siegel, and Smith 1988), patents and R\&D (Pakes 1986), and real estate (Titman 1985, Williams 1991, Williams 1993 and Grenadier 1996). Lander and Pinches (1998) summarize the applied literature.
} 
volatility. ${ }^{3}$ These papers have sometimes found limited evidence of a link between investment and volatility (e.g., Hurn and Wright 1994), although recent work has tended to be more supportive of real options. Bell and Campa (1997) demonstrate that the volatility of exchange rates has a negative effect on new capacity investment in the international chemical industry, but that the volatility of input prices and demand have small and insignificant effects. Downing and Wallace (2001) find a negative link between volatility of prices and costs and the decisions of homeowners to improve their homes. More recently, Moel and Tufano (2002) examine the determinants of the decision to close or re-open a mine using a sample of 285 gold mines. They find that gold price volatility has a negative and statistically significant effect on these decisions, but that factors such as firm-specific managerial decisions also matter.

We take advantage of micro-data on a large number $(1,214)$ of condominium developments and examine the impact of volatility using relatively disaggregated neighborhood output (condominium) prices in an approach that is similar to Moel and Tufano (2002). Moel and Tufano use detailed data on the operating and maintenance costs for mines and the convenience yield (rental value) of gold to estimate a reduced-form probit model of the determinants of opening and closing a mine. Their strength is in the detailed data on costs and convenience yield and the precise measurement of mine opening and closing. In this paper we use the same basic methodology, a reduced-form hazard model. Yet we focus on price volatility instead of cost volatility for the following reasons: First, volatility in construction cost components such as wages and materials represent a relatively small portion of the variability in

\footnotetext{
${ }^{3}$ Quigg (1993) takes a different approach. She develops a structural model of land valuation using data in Seattle, finding that the option to wait is worth about 6 percent of the value of undeveloped industrial land, a relatively low value.
} 
the profits of builders relative to the volatility of selling prices. Second, interest rates are more important for developers, but the impact of interest rate volatility cannot be reliably disentangled from price volatility. Third, we can use neighborhood price indexes to obtain cross-sectional and time-series variation in price volatility, but we only have aggregate data on costs. Fourth, work by Somerville (1999) indicates that construction cost indexes perform poorly in models of housing supply, because of errors in index construction and the endogeneity between housing starts and local unobserved costs.

However, our study provides some important enhancements to previous studies. This is the first study of real options and investment that we know of that differentiates between the impact of systematic (market) and non-systematic risk. In addition, we examine the prediction that the extent of competition can mitigate the negative relationship between uncertainty and investment. By quantifying different types of risk and also the extent of competition, we hope to exploit those factors present in a real options characterization, but not in more standard discounted cash flow or CAPM investment frameworks. This allows us to differentiate between effects found in a real options model from simply observing that uncertainty negatively impacts development, a prediction not unique to real options models. ${ }^{4}$ Evidence that competition diminishes the relationship between investment and idiosyncratic risk would support a real options interpretation because it is difficult to find a comparable prediction in a model of risk aversion that does not rely on real options behavior.

\footnotetext{
${ }^{4}$ Systematic risk is predicted to reduce investment in a variety of models (including the CAPM) via the cost of capital where non-systematic risk is not priced. Real options models predict a negative impact of non-systematic risk on investment. An unobserved investment-specific discount rate that is correlated with aggregate uncertainty will yield a negative relationship between volatility and investment, but would be insufficient to prove real options behavior.
} 
One potential complication is that our data contain a mix of large national developers and medium and small-sized local developers. We cannot explicitly identify the developers of individual projects from the data, as most developments, even those by large public developers, are typically done by wholly-owned shell companies, one per development. Evidence from other work indicates that the vast majority are small and medium-sized local developers, with some national developers and individual developers from Asia. ${ }^{5}$ Clearly these various types of developers may react differently to idiosyncratic risk. Risk aversion on the part of small developers might lead them to delay investment if they cannot hedge the risk, which must be true for local (Vancouver) real estate price risk. Our results regarding competition are quite important in this regard, as they are direct predictions from real options models that do not arise from the traditional DCF investment models and cannot easily be tied to risk aversion by small local developers who might hold undiversified portfolios.

\section{EMPIRICAL SPECIFICATION}

We begin by characterizing some of the basic features of the standard, partial-equilibrium real options model to convey some intuition. We then discuss issues specific to the real estate market that may alter the forces at work in this simple framework. We consider how these issues may change the standard predictions, and how we try to address them in our empirical analysis.

Most real options models solve for the price level that triggers new investment, $P^{*}$, so that when $P>P^{*}$, the owner will choose to make an irreversible investment. In the simplest form

\footnotetext{
575 percent of projects in a larger sample of developments in the Vancouver metropolitan area were constructed by developers who built fewer than 13 projects between 1970 and 2002.
} 
of the model, the only source of uncertainty is the path of future asset prices ${ }^{6}$ and investments are completely irreversible, thus ignoring the put option to sell for an alternative use. The asset price evolves as a geometric Brownian motion process:

$$
d P / P=\alpha d t+\sigma d z
$$

where $\alpha$ and $\sigma^{2}$ are the drift (expected capital appreciation) and variance parameters, respectively, and $d z$ is the increment of a Wiener process. The asset is also assumed to have a constant, convenience (dividend) yield $\delta$. A closed form solution can be found by dynamic programming or contingent claims pricing, assuming that there are securities in the economy that span the risk in $\mathrm{P}^{7}$ As in the familiar option pricing formula of Black and Scholes (1973), the trigger price is:

$$
P^{*}=f\left(\mu^{+}, \delta^{-}, \sigma^{+}\right)
$$

where $f$ is a non-linear function, $\mu$ is the discount rate (equivalent to the expected rate of return on the asset), and the superscript sign represents the expected sign of the effect of an increase in each of these parameters on $P^{*}$. The usual comparative static results from option pricing theory apply: the trigger price for new investment is increasing in the discount rate, increasing in the volatility of returns and decreasing in the convenience yield. ${ }^{8}$

\footnotetext{
${ }^{6}$ Williams (1991) and Quigg (1993), for example, assume cost uncertainty in addition to price uncertainty. In Grenadier (1996, 2002) and Novy-Marx (2005), it is the underlying demand shock that follows a geometric Brownian motion process. Consequently, the endogenously derived price process evolves as a reflected Brownian motion that is affected by aggregate supply in addition to the demand state variable.

${ }^{7}$ Quigg (1993), for example, assumes that there exists an equilibrium in which contingent claims on both building prices and development costs are priced uniquely. See Dixit and Pindyck (1994) for more detail on these models.

${ }^{8}$ Ideally, we would be able to observe the exact determinants of all factors that determine $P^{*}$, including the cost of development and profitability at each site for each point in time, enabling structural estimation of $f$. Unfortunately, such variables are difficult to obtain.
} 
The specification for the discount rate depends on the assumptions regarding risk preferences and complete markets. If investors are risk-neutral the discount rate is the risk-free rate of return, usually assumed to be the interest rate on a short-term government security. Alternatively, if investors are risk-averse but markets are complete, the return on an asset can be derived from the capital asset pricing model (CAPM):

$$
\mu=r_{f}+\phi \rho_{p m} \sigma
$$

Here $r_{f}$ is the risk-free rate of return, $\phi$ is the market price of risk, $\sigma$ is the standard deviation of the excess returns on the asset, and $\rho_{p m}$ is the correlation between excess returns on the asset, in our case real estate, and excess returns for the broader market. Finally, if markets are in equilibrium but are incomplete and investors are risk averse, we can use a project specific discount rate, $\rho$, as the sum of expected capital appreciation and the convenience yield, as follows:

$$
\rho=\alpha+\delta
$$

In the empirical work, it is important to properly control for the discount rate, since volatility might reduce the likelihood of investment not because of real options behavior, but instead because investors or real estate developers are risk averse and volatility enters the discount rate directly. For example, in the CAPM, systematic risk reduces the likelihood of investment, not due to any effect of irreversible investment, but instead because investors cannot fully hedge systematic or market risk. Below, we choose to include several alternative proxies for the (unobserved) discount rate, including estimates of the risk-free rate, the CAPM discount rate, and a project-specific discount rate derived from the relationship in equation (4). With incomplete markets for real estate assets and many individual investors who are likely risk 
averse, we would expect that risk factors will play a role. So, for example, the discount rate $(\mu)$ should depend, at least in part, on the covariance between the volatility of local real estate prices and aggregate risk, as in the CAPM.

The traditional model described above assumes that prices follow geometric Brownian motion with a constant drift and variance. However, existing empirical work strongly suggests that real estate prices exhibit short-run positive serial correlation and long-run mean reversion. ${ }^{9}$ In addition, the volatility of asset returns have been shown to vary over time. Yet even when the random walk assumption is relaxed and the volatility of returns is taken to be stochastic, assumptions which more closely replicate the circumstances in our data, the qualitative predictions of the model still hold. For example, Heston (1993) derives a closed-form solution for pricing options in a model with time-varying stochastic volatility. He finds that, similar to Black-Scholes (1973), a higher variance still increases the price of an option. ${ }^{10}$ When both mean reverting interest rates and the convenience yield are stochastic, Miltersen (2000) finds similar qualitative effects, but with a lower option value than in the standard Black-Scholes (1973) framework. Schwartz (1997) uses numerical methods to obtain comparative statics for a model with stochastic factors in mean reverting prices, mean reverting convenience-dividend- yields and time-varying interest rates. Even in this more complicated world, the usual real options results hold, with the exception that option values become less sensitive to prices when there is mean-reversion in prices. Finally, Lo and Wang (1995) show that with auto-correlation in

\footnotetext{
${ }^{9}$ See Case and Shiller (1989), Meese and Wallace (1993), and Quigley and Redfearn (1999).

${ }^{10}$ The stochastic volatility assumption affects the kurtosis and skewness in the distribution of spot returns.
} 
returns, the option-pricing formula is unchanged. ${ }^{11}$ All of these findings suggest that the usual real options prediction that the investment trigger price increases with uncertainty would still apply to the real estate market.

In models such as Williams (1991), Quigg (1993), and Dixit and Pindyck (1994), costs play an important role in determining the trigger price for investment. Assuming that the cost process follows geometric Brownian motion, $P^{*}$ would be increasing in both costs and cost volatility. For the reasons outlined earlier, we ignore the volatility of costs and focus instead on prices.

Without detailed cost data and the ability to properly estimate builder profits and thus a specific hurdle rate for prices, $P^{*}$, our empirical approach is to identify the principal implication of higher trigger prices, i.e. that investment is delayed. Below, we look at the time from an arbitrary starting point (January 1979) until development occurs. Explicitly, we estimate the hazard rate of investment $h(t)$, defined as the conditional probability of development occurring at time t, as:

$$
h(t)=\operatorname{Pr}\left(P_{t} \geq P_{t}^{*} \mid P_{x}<P_{x}^{*}, \forall x<t\right)
$$

Given the current price level, the hazard rate is decreasing in the price trigger $P^{*}$. We can therefore estimate a reduced form hazard specification, where the hazard rate is a function of the determinants of $P^{*}$, holding the current price level fixed. The hazard has the following empirical specification:

$$
\boldsymbol{h}(\boldsymbol{t})=\exp \left(\boldsymbol{X}_{\boldsymbol{t}}{ }^{\prime} \boldsymbol{\beta}\right) \boldsymbol{h}_{0}(\boldsymbol{t})
$$

where $X_{t}$ is a vector of explanatory variables and $\beta$ is the vector of coefficients to be estimated.

\footnotetext{
${ }^{11}$ They show that if the unconditional variance of returns is held constant, changes in the predictability of returns implies that the diffusion coefficient must also change over time.
} 
As described in more detail below, we allow the price level and the volatility of condo returns to change over time. The base model assumes a Weibull distribution for $t$; that is, the baseline hazard rate, $h_{0}$, is monotonically increasing or decreasing over time. ${ }^{12}$ We examine alternative distributions as well in the empirical results that follow.

\section{DATA DESCRIPTION}

We use data on all strata (or condominium) projects with at least four units per project built in the city of Vancouver, Canada between January 1979 and February 1998 - a total of 1,297 projects. Projects are identified according to the date that the government responds to the developer】s filing of a strata plan to convert the single title for the land into multiple strata (condominium) titles. ${ }^{13}$ By law this can only occur near the completion of construction. We convert the granting of a strata title to the start of construction by introducing a one-year lag in the dependent variable. ${ }^{14}$

Over this period there are several bursts of development activity. Figure 1 shows four peaks in the number of strata real estate projects in 1982, 1986, 1991, and 1996. In addition, there has been a large secular increase in the average project size. The increase in condominium

\footnotetext{
${ }^{12}$ Under the Weibull specification, $\boldsymbol{h}_{0}(\boldsymbol{t})=\boldsymbol{p} \boldsymbol{t}^{p-1}$. If $p>1$, then the baseline hazard rate is monotonically increasing, if $p<1$, the baseline hazard is monotonically decreasing, and if $p=1$, the baseline hazard is a constant (which is equivalent to an exponential distribution for $\mathrm{t}$ ).

${ }^{13}$ In British Columbia condominium units are those with a strata title to allocate ownership of the land among the units. Strata title legislation was first enacted in British Columbia in September 1966 and the first units under this legal form were built in 1968. While non-residential strata-titles exist, over 95 percent of strata projects are residential. For a discussion of strata title legislation and the first years of strata development in British Columbia see Hamilton (1978).

${ }^{14}$ Nearly all real estate development is primarily debt financed. Lenders have strong incentives to ensure that construction occurs as expeditiously as possible, which is reflected in the loan terms. Developer equity is the first in and last out. Consequently, assuming an exogenous lag is not unreasonable, as there is little incentive to delay construction.
} 
development activity over this time period was much greater than the growth in single family construction, both in the City of Vancouver, because of an absence of undeveloped land, and even in the metropolitan area. Local commentators describe the mid-1980's as the point at which a broad, general acceptance of the strata form of ownership began, so that over this period the growth in strata projects exceeded that of single family developments.

Table 1 presents the descriptive statistics for the monthly data used in the paper, including citywide and neighborhood prices, the volatility of returns, expected price appreciation, the project specific discount rate, systematic risk, and the extent of competition across projects. The construction of these variables is described below. All data are presented in real terms. ${ }^{15}$

We compute monthly repeat sales indexes of condominium prices, using data obtained from the British Columbia Assessment Authority (BCAA) of all condominium transactions from 1979 to 1998 . A repeat sales index has the advantage of controlling for changes in the quality of aggregate characteristics of units sold over time because it is composed of the change in the prices of individual units and is not a market average. ${ }^{16}$ We create separate price indexes for seven sections of the city according to BCAA neighborhood boundaries using the geometric repeat sales methodology outlined in Shiller (1991). Three neighborhoods are unique while the other four are amalgamations that are geographically contiguous, demographically similar, and

\footnotetext{
${ }^{15}$ We deflate with the moving average of the monthly inflation rate for the previous 6 months with declining weights by month.

${ }^{16}$ These condominium data are less susceptible to some of the flaws of repeat sales indexes. First, it is very hard to add to or substantially renovate these units, so unit quality and quantity are more likely to remain constant over time. Second, these units transact more frequently than do single family units, so we discard fewer transactions when requiring that units used for the repeat sales index must sell at least twice over the sample period. See Thibodeau (1997) for a summary of the issues associated with computing real estate price indexes.
} 
have sufficient transactions to create a monthly price index. We exclude 83 projects in neighborhoods that are difficult to combine into homogenous sub-markets, leaving a total sample of 1,214 units.

Although we use neighborhood price indexes in all of the regressions that follow, Figure 2 presents the city-wide real price index for Vancouver condominiums. Our period of analysis covers three clear real estate price cycles. The first is a striking run-up between mid-1980 and mid-1981 followed by a sharp fall ending in mid-1982. The second is the 1988-1990 increase in prices that coincided with the post-Tiananmen Square wave of immigration from Hong Kong. The third is the much more moderate 1991-1994 period of increasing prices. Between 1994 and 1998, real condominium prices in Vancouver fell approximately 15 percent.

To measure uncertainty, we compute a time-varying measure of the volatility of monthly neighborhood returns. First, we use an autoregressive model of returns on lagged returns to predict future real estate returns. We then apply a $\operatorname{GARCH}(1,1)$ model to estimate the variance of the residuals from the first stage prediction. This GARCH specification incorporates the serial correlation in returns and time-varying volatility discussed in the previous section, which is more appropriate to real estate prices than geometric Brownian motion. Using conditional maximumlikelihood, we obtain estimates of the conditional variance of monthly neighborhood returns given past prices, while controlling for the predictability in returns. The structure imposed by the GARCH model will not change the qualitative predictions of the real options model: Bollerslev, Chou and Kroner (1992) maintain that the simple structure imposed by the GARCH model can be viewed as a reduced form of a more complicated dynamic process for volatility. ${ }^{17}$

\footnotetext{
${ }^{17}$ Heston and Nandi (2000) show that a more general form of the GARCH $(1,1)$ process approaches the stochastic volatility model of Heston (1993) in the continuous time limit.
} 
We also consider two additional measures of uncertainty. The first is the simple variance in monthly neighborhood returns over the previous two years. The second is the same GARCH specification described above, but with a correction for the component of volatility caused by differences in the ratio of repeated sales of the same unit to the total transactions in a month. In using a repeat sales index, we include those transacting units for which there is at least one additional transaction in the sample. However, we expect a developer to make an assessment based on all transactions in the market. ${ }^{18}$ The three series of monthly return volatilities are presented for the city-level in Figures 3a and 3b for 1979-1998 and for the sub period 19861998, respectively. Return volatilities are substantially lower in the 1986 to 1998 period because we exclude the 1981 price spike and the period at the start of the sample where total transactions are low because of the small number of condominium units. The volatility series for each of the seven neighborhoods displays these same characteristics as well.

The appendix shows the results of the GARCH estimation using transactions-adjusted returns. The coefficients on lagged returns provide evidence of short horizon negative serial correlation, even though underlying real estate returns have positive long-run serial correlation. ${ }^{19}$ The repeat sales indexes have the characteristic that estimated volatility is higher, on average, during periods when the underlying index has fewer transactions. We believe that this pattern

\footnotetext{
${ }^{18}$ We correct for this potential bias by scaling mean returns to zero and then multiplying the calculated return for a given month by the square root of the ratio of repeat sales transactions to total transactions. The adjusted GARCH measure effectively smooths volatility as the share of sales in the repeat data base falls, offsetting a higher measured variance in months where we have relatively fewer repeat sales. We thank Robert Shiller for pointing out this issue and suggesting this correction.

${ }^{19}$ The coefficients on lagged returns are negative in all neighborhoods. This finding is consistent with what often happens with a repeat sales index of real estate prices. The presence of an unusually high price in one period biases the index upward in the current period, resulting in a negative return next period. See Case and Shiller (1989) for a discussion of price indexes and serial correlation in real estate returns.
} 
captures an important source of uncertainty faced by developers. In the typical search model, a thin market with relatively few transactions has greater underlying price uncertainty than a thick market with many transactions. When fewer transactions take place, developers have difficulty extracting signal from noise.

We believe that the volatility forecasts from the transactions-adjusted GARCH model is the appropriate measure to use in the regressions that follow, although the same basic results hold for the unadjusted GARCH volatility forecasts. Most of the previous literature has measured volatility as a weighted average of past returns. However, it is the ex-ante estimate of expected volatility that is needed for decision-making. ${ }^{20}$ Real options models predict that developers will use a forward-looking measure of volatility, such as that derived in our GARCH model, in deciding when to exercise their development option. In Figures $3 \mathrm{a}$ and $3 \mathrm{~b}$, it is clear that the transaction-adjusted GARCH measure represents a lower bound relative to the other two volatility measures.

We compute expected price appreciation, $\alpha$, from an auto-regressive process up to order three for each of the neighborhood return series. Expected price appreciation (the drift rate) is the one month ahead return forecast from this specification. The project specific discount rate, $\rho$, is defined as the sum of expected price appreciation, $\alpha$, and the monthly dividend yield, $\delta$, as in equation (4). The dividend yield is derived from a combination of our price indexes and the CMHC (Canada Mortgage Housing Corporation) rent surveys. ${ }^{21}$

\footnotetext{
${ }^{20}$ See Andersen, Bollerslev and Diebold (2002) for a survey of the different parametric and nonparametric volatility estimation techniques.

${ }^{21}$ We use cross-sectional rent levels from the annual CMHC rental survey and neighborhood specific prices from our data to fix a neighborhood specific dividend yield. The price component of this yield then varies over time with our neighborhood repeat-sales price indexes, while the rent component varies with the Statistics Canada metropolitan area rent index (neighborhood specific rents are only available for part of our analysis period and then only on an annual or semi-annual basis).
} 
Finally, we measure exposure to market volatility, as in the CAPM, by multiplying the monthly Toronto Stock Exchange (TSE) 300 market return volatility ${ }^{22}$ by a time varying measure of the CAPM $\beta$, the covariance between excess returns in the Vancouver condo market and the TSE 300. Most studies of the stock market also show that individual stock $\beta$ s appear to change over time. To estimate a time varying measure of beta we use Cleveland and Devlin's (1988) locally weighted regression methodology. This non-parametric specification estimates $\beta$ using a weighted sub-sample of the time series, with heaviest weights on the closest time periods (Figure 4). ${ }^{23}$

\section{EMPIRICAL RESULTS}

The hazard model in equation (6) is estimated by maximum likelihood. The baseline hazard rate, $h_{0}$, reflects the probability of development as a function of time alone. The explanatory variables will affect the probability of development multiplicatively by the factor $e^{\beta}$. The null hypothesis of $\beta=0$ corresponds to a coefficient of 1 in the hazard model. Hence, in the regressions that follow, the coefficient on a variable $X$ that we estimate is the proportional effect on the hazard rate of a unit change in $X$. An estimated coefficient greater than one in the regression output suggests that an increase in the variable has a positive impact on the baseline hazard--that is, a higher probability of development--while a coefficient less than unity implies

\footnotetext{
${ }^{22}$ TSE 300 return volatilities are calculated using a GARCH(1,1) model.

${ }^{23}$ For each month, the excess neighborhood returns are regressed against excess TSE 300 returns using the nearest $60 \%$ of months in the sample. These observations are weighted using a tri-cubic function so that the weight for a month declines with distance in time from the month for which we are estimating the beta.
} 
the reverse effect. ${ }^{24}$ We estimate heteroskedasticity-consistent standard errors that allow for correlation across time in the hazard rate of individual projects (the Huber/White estimator of variance clustered on each individual project).

One complication is that we do not observe the start date for construction. When the developer files a strata plan, the building is almost completed and ready for sale. However, the actual investment (option exercise) takes place months earlier when the developer begins physical construction of the project. To compensate, the date of our dependent variable is lagged by one year to reflect the time required for physical construction. Somerville (2001) shows that 59 percent of new multi-family projects are completed within one year of the start of construction. This built-in lag also reduces or eliminates any possible problems relating to simultaneity between prices and new construction. Reducing the lag length to six or nine months has little impact on the results. To control for differences in construction time, we include linear, quadratic and cubic terms for project size and dummy variables for building type in the regressions.

\section{A. Base Specification}

The first three columns in Table 2 present maximum likelihood estimates of our base specification with the three alternative measures of the project discount rate, $\mu$. All regressions use neighborhood-level prices and volatilities, building type, project size variables and neighborhood fixed effects. ${ }^{25}$ The regression coefficients are generally of the expected sign for

\footnotetext{
${ }^{24}$ In the regressions below, a one unit change in $\mathrm{X}$ leads to a $\left(e^{\beta}-1\right)$ percent change in the hazard rate. For example, a coefficient of 1.05 implies that a one unit change in $\mathrm{X}$ increases the probability of development by $5 \%$.

${ }^{25}$ We estimated the model with neighborhood fixed effects at the most disaggregated level (according to the BCAA classification) to incorporate more heterogeneity into the model without sacrificing too many
} 
the real options model and are almost uniformly statistically different from one. Not surprisingly, developers choose to develop a parcel more quickly when neighborhood prices are higher. Price coefficients are greater than one in six of the seven neighborhoods and statistically significant in five of those neighborhoods. Even controlling for prices, however, the coefficient on the volatility of condo returns is less than one and statistically significant at the 95 percent confidence level in all specifications, suggesting that developers wait longer to develop when the volatility of returns is higher. The coefficients on volatility suggest economically important effects. In column (1), a one standard deviation increase in the condo return volatility (35 percent) decreases the monthly hazard rate of development by 13 percent. Evaluated with the average neighborhood price coefficient of 1.014 , this increase in volatility is equivalent to a 9 percent decrease in prices. $^{26}$

We choose not to include the convenience yield $\delta$ in the regressions we present here, instead substituting with the expected price appreciation $\alpha$ (equation 4). As described in the previous section, we are unable to generate monthly quality-controlled neighborhood-level rent indexes. We find that the drift rate $\alpha$, has little impact on the probability of development. Finally, as many builders point out, the risk-free interest rate, the real short-term Canadian T-Bill rate, has a large impact on construction. A one percentage point increase in the risk-free rate leads to a 52 percent decline in the monthly hazard rate.

In column (2) we include a separate control for systematic risk based on the CAPM, the degrees of freedom. The results are similar (with mostly higher z-statistics) to those reported here.

${ }^{26}$ Papers on housing supply such as DiPasquale and Wheaton (1994) and Mayer and Somerville (2000) find that controlling for house prices, starts or permits consistently fall in non-price measures of demand such as expected time to sale. We also run the model including the level and volatility of two other measures of demand, existing single family home sales and the ratio of units listed for sale to actual sales. We find that increases in the volatility of sales or the ratio of listings to sales also leads to a statistically significant decline in the hazard rate. 
market risk component of condominium return volatility. This is measured as the neighborhood condo $\beta$ multiplied by the volatility of the TSE 300 index. As expected, adding market volatility decreases the effect of idiosyncratic volatility somewhat - the coefficient on idiosyncratic condo return volatility moves closer to one, from 0.9961 to 0.9968 , but it remains statistically different from one and economically important. The coefficient on market volatility is 0.8371 and is statistically different from one with 90 percent confidence. In this case, a one standard deviation increase in the average market volatility across the neighborhoods $(0.45)$ leads to an 8 percent decline in the hazard rate, while an equivalent one standard deviation increase in idiosyncratic volatility leads to an 11 percent decrease in the hazard rate.

Our measure of the project specific discount rate does not perform as well as the other proxies for the actual discount rate-it is small and statistically insignificant in the third column. The project specific discount rate is measured as the sum of the dividend yield and expected short-term appreciation. There are a number of possibilities why this project specific discount rate does not perform very well. First, this measure of $\rho$ does not exhibit much time series variation in the dividend flow, so it is strongly correlated with $\alpha$. In addition, as noted in section III, the model that uses this measure of the project specific discount rate makes the questionable assumption that the real estate market is in perpetual equilibrium. Previous research (Case and Shiller (1989) and Meese and Wallace (1993)) suggests that real estate markets exhibit important periods where prices are inefficiently determined over the real estate cycle. As a result, the remaining regressions use the second measure of the discount rate (column 2) based on the CAPM, so that the project discount rate is equivalent to the risk free rate plus an adjustment for market risk.

An insignificant coefficient on $\alpha$, the expected price appreciation parameter, is consistent 
with the standard real options model in which the hurdle rate is independent of the drift rate. However, one might be concerned that volatility is picking up factors related to periods of rapidly increasing or decreasing prices that might have an independent effect on investment. For example, given the positive short-run serial correlation in prices that has been documented in many markets, a developer might choose to delay construction in anticipation of further short-run price increases. Alternatively, rising prices can provide capital gains that allow developers to overcome liquidity constraints, enabling them to pursue a larger number projects. Thus future expected price increases might lead to a greater hazard rate of new construction.

More interestingly, Grenadier (1996) raises the possibility that falling prices could also trigger a cascade of development. In a game theoretic model with two owners of competing parcels, Grenadier demonstrates the existence of a "panic" equilibrium where developers each race to build before prices fall too far. As in the prisoner's dilemma, both developers choose to build rather than be preempted. In the Grenadier framework, holding the price level constant, both expected price increases and decreases can spur development activity. We believe that the relevant sphere of competition for a given project is not the entire market, but a more narrow geography where the scope of competition is smaller. This makes Grenadier's argument more compelling.

In column (4) we differentiate between positive and negative expected price appreciation. These variables are calculated by multiplying $\alpha$ by a dummy variable that equals one if $\alpha$ is positive (negative) and zero otherwise. In fact, the inclusion of these terms does not affect the coefficient on volatility. However, the coefficient on positive expected price appreciation is above one while the coefficient on negative expected price appreciation is less than one, with both coefficients significant at the $5 \%$ level. These results suggest that holding price constant, 
development is more likely when prices are rising faster and when prices are falling faster. (For the latter, the negative coefficient interacts with negative price changes to produce the positive effect on the hazard.) This result supports Grenadier's strategic behavior analysis of the "price equilibrium" as well as arguments for increased development during periods of rapid price changes. The quadratic relationship between the hazard and price appreciation explains why the estimated coefficient on the simple $\alpha$ was not statistically different from one.

In Table 3 we test for robustness, running these regressions over different time periods and for different hazard distributions. Over a three year period (1981-83) real prices in Vancouver rose by $100 \%$ and then fell to their original level. Elevated volatility over this period could dominate the data and drive the relationship between volatility and new construction. In column (1) we run the model using data from 1986-98 only. The statistical significance of prices drops considerably in this later time period, but the coefficient on the volatility of condo returns remains below one and is statistically significant at the 10 percent level or better. The coefficients on the risk free rate and overall market volatility are also below one and are highly significant.

One might also be worried that our findings might be tainted by the sequential nature of investments in real estate developments. The presence of dual options to invest and disinvest by redeploying buildings to other uses might complicate the real options prediction of a negative relationship between irreversible investment and uncertainty. ${ }^{27}$ However, the condominium projects in this paper are quite difficult to shift to alternative locations or uses - an assessment

\footnotetext{
${ }^{27}$ For example, Abel, et. al. (1996) argue that when capital is at least partially reversible, an investment in a real asset has a call option, the ability to delay investment, and a put option, the opportunity to disinvest and deploy that asset in an alternative use. Uncertainty raises the value of the call option, increasing the user cost and reducing investment, but it may also raise the value of the put option, increasing investment. Bar-Ilan and Strange (1996) also find that delays can reverse the traditional negative correlation between uncertainty and investment in circumstances with sequential option exercise.
} 
confirmed through discussions with market participants. For example, most condominium projects pre-sell some individual units, which automatically precludes the developer from changing the use. Zoning restrictions will also prevent such conversions, without long time lags and high costs. Finally, the nature of development finance creates strong incentives for project completion. ${ }^{28}$ Additional evidence comes from the fact that conversion between residential and office uses are still exceedingly rare. Nevertheless, we address this possible censoring in projects that actually file a strata plan since, for example, a developer may start and subsequently abandon a project prior to filing a strata plan. ${ }^{29}$ To do this, we artificially censor the data on our own by truncating the sample in 1994, but include all (unbuilt) projects in the data. The assumption in this part of the analysis is that projects that are abandoned in the previous downturn in 1994 will be subsequently completed when prices rose again by 1998. The second column of Table 3 tests for any censoring bias that may be due to the abandonment of projects that we do not observe. Again, although the statistical significance of prices is slightly reduced, the findings for volatility remain unchanged. The coefficient on the risk free rate, however, is now significant only at the 10 percent level, while the coefficient on systematic risk is not significant at all. These results show that censoring has the effect of biasing the coefficients toward zero. Thus, it is likely that we underestimate the impact of risk and prices on the

\footnotetext{
${ }^{28}$ Most new developments use relatively high leverage. Once a project has been granted financing, loan agreements typically make future draws on the construction loan contingent on reaching certain (engineering) stages in the construction process. Given that the developer has put his own money into the project up front, if the developer stops prior to completion, he will likely lose all of his equity. If the developer continues with the project, there is always a chance that the market will improve. In this case there is a nearly costless put option on the completed project that is extinguished by abandoning prior to completion.

${ }^{29}$ Somerville (2001) finds that new information on market conditions and demand shocks have no effect on the rate at which units under construction are completed, conditional on the number of units started. It is more common that developers start preliminary work on zoning and permitting issues and then abandon before permits are even issued.
} 
likelihood of development.

In column (3) we rerun the base specification using an exponential distribution for the underlying hazard, which assumes a constant baseline hazard rate $h_{0}$. In column (4) we use the lognormal distribution, which allows the baseline hazard rate to be single-peaked. The latter is estimated in accelerated failure time and coefficients are reported in unexponentiated form, so that positive coefficients lead to increases in survival time (decrease in the hazard rate) and negative coefficients indicate a decrease in survival time. In both specifications the coefficients on systematic and idiosyncratic volatility are statistically significant, so increases in volatility lead to decreases (increases) in the hazard (survival) rate. The real risk free rate also has the expected sign and is statistically significant. The data suggests that the Weibull model is the preferred specification using the Akaike information criterion. Moreover, in all Table 2 specifications, the log-likelihood test strongly rejects the hypothesis that the estimated Weibull parameter is equal to unity, and is in fact greater than one - supporting the assumption of an increasing baseline hazard. As expected, this specification is consistent with the fact that we only observe completed projects in our data. It is important that we use a model that captures this feature of our data. Our primary interest is not in the underlying hazard function per se, but on the effect of the time-varying covariates on the hazard. Thus, we use the Weibull specification in the remaining regressions.

\section{B. Competition}

We now examine the impact of competition on real option exercise. Not only can this evidence help resolve the theoretical debate about the role of competition in option exercise, it also allows us to consider the extent to which risk aversion explains some of our results. In the 
regressions above we control for a variety of factors that might be part of the project specific user cost, but are unrelated to the option to develop. Nonetheless, it remains possible that idiosyncratic volatility impacts investment through risk-averse real estate developers, rather than through a higher hurdle rate on the call option to make an irreversible investment. The effect of competition on option exercise offers a test of this hypothesis because the risk aversion model presents no reason that the correlation between idiosyncratic volatility and option exercise should be related to the degree of competition faced by a project.

To test this model, we examine the coefficient on the interaction between competition and uncertainty. If competition reduces the value of the option to delay, then the estimated coefficient on the interaction term will be greater than unity. In this case, the negative effect of volatility on the hazard rate of development is weakened, i.e. less negative and smaller in absolute value.

We measure competition by the number of competing projects within a given distance of each development site. We believe that the relevant sphere of competition for a given project is not the entire market, but a more narrow geography where the scope of competition is smaller. At each point in time that project $i$ in our sample has not yet been developed, we count the number of other potential, but as of yet unbuilt, projects within a one or two kilometer radius from project $i$. This measure is the actual number of all future developments that will be built around the development site $i$. To address the problem that our measure of competition naturally leads to a reduction in the number of competitors as time moves closer to the end of the sample, we include all projects in the sample up to 1998, but run the regressions only up to 1994 . Furthermore, we compare the results using alternative measures of the relevant time horizon, counting all the projects that will be built in the future in our data and only those to be built in 
the next 4 years.

Table 4 presents regressions that include the various measures of competition, a variable for volatility, plus an interaction term for competition and condo return volatility. The results are consistent with the theoretical prediction that competition reduces the value of the option to wait. In all four columns, the coefficient on volatility is below one and significant, while the coefficient on the interaction between competition and condo return volatility is greater than one and significant at the $10 \%$ level or better. This indicates that volatility has a smaller impact on option exercise in locations that face greater potential competition. Consider the estimates in column (4), where competition is measured as the number of projects four years into the future within a one kilometer radius. At the mean number of potential projects (23), a one standard deviation increase in condo return volatility (35\%) leads to a 13 percent decline in new construction, which is slightly bigger than our earlier estimates in Table 2. However, if the number of competitors increases by 50 percent, the same one standard deviation increase in volatility only leads to a 9 percent decrease in the hazard rate. Thus as a project is surrounded by more competitors, its hazard rate of construction becomes less sensitive to volatility.

Competition appears to operate only by reducing the impact of volatility. In all cases, the coefficient on competition itself is never close to statistical significance at conventional levels. This finding addresses another possible complication in our regression: that competition is endogenous. If the number of competitors were larger in neighborhoods where demand was unobservably high, we would have expected that a larger number of competitors would have been positively correlated with option exercise. Yet competition only appears to be correlated with new construction when interacted with volatility. This result is consistent with our experience in this market. We expect that the number of potential competitors is more likely 
related to exogenous factors such as the type of buildings constructed in previous decades as well as pre-existing zoning requirements.

The coefficients on the other variables are of the expected signs and are similar to the base regressions in Table 2. The exceptions are that the magnitude and significance of the risk free rate are reduced and systematic risk is now insignificant. The identification for these two variables comes from time series variation alone, whereas we have cross-sectional variation in the real price indexes, so we lose a lot of power when we shorten the time horizon in these regressions.

As an alternative, Table 5 measures competition as the number of condominium units in each potential project, and not just the number of potential projects. In this sense we differentiate between large and small projects, and also account for the increase in project size over time. Nonetheless, the impact of competition on volatility remains unchanged. In all columns, the interaction between the number of competitors and volatility is above one and significant at the 8 percent level or better and the coefficient on volatility is below one and highly significant as well. The coefficients on prices and other variables are similar to those coefficients in the previous table.

As an additional robustness check, we estimate the Weibull model with a shared frailty component, i.e. we introduce unobservable group heterogeneity into the hazard function that is neighborhood specific ${ }^{30}$. This specification addresses strategic interactions between projects in the same neighborhood since it is quite likely that individual developers will account for the exercise decisions of their neighbors when making their own decisions to invest. The

\footnotetext{
${ }^{30}$ We try both gamma and inverse-Gaussian distributions for the frailty parameter with similar results. See Gutierrez (2002) for more details.
} 
assumption here is that projects within the same neighborhood are correlated and have a common underlying probability of development. The results with this frailty specification and the competition variables are similar to those reported here. Moreover, the frailty parameter is insignificant suggesting that neighborhood hazards have no separate effect from the individual project hazards. $^{31}$

\section{CONCLUSION}

The results in this paper support many of the conclusions from the burgeoning theoretical literature on the importance of real options and competition. Our empirical estimates suggest that builders delay development during times of greater idiosyncratic uncertainty in real estate prices and when the exposure to market risk is higher. These findings hold across different time periods. The impact of volatility in our sample is large and statistically significant in most specifications. A one standard deviation increase in condominium return volatility leads to a 13 percent decline in the hazard rate of investment, the same effect as a 9 percent decline in prices. Similarly, our estimates suggest that the hazard rate falls 8 percent when exposure to systematic risk increases by one standard deviation.

We also show that competition significantly reduces the sensitivity of option exercise to volatility. Increases in competition appreciably decrease the coefficient on volatility in our hazard rate specification. In fact, volatility has no estimated effect on option exercise for the 5 percent of our sample with the largest number of potential competitors. This finding is fully consistent with Caballero (1991), Trigeorgis (1996) and Grenadier (2002) who argue that

\footnotetext{
${ }^{31}$ Frailty estimation of our base regression in Table 2 (column 2) yields a statistically significant frailty parameter, indicating that in addition to individual hazards that are increasing over time, there is a separate neighborhood hazard that increases over time as well. Our main findings however, are unchanged.
} 
competition diminishes the value of waiting to invest. The erosion in value of the investment opportunity due to one's competitors creates incentives to invest earlier. Hence competitive firms are not able to capture the full benefits to waiting that a monopolist has. This result supports the real options model because the interaction between competition and volatility should not affect the user cost of a reversible investment. This provides clearer evidence in favor of the real options model rather than the alternative that risk averse developers choose not to build at times of greater uncertainty.

From a policy perspective, these results have important implications for understanding real estate cycles. An often-repeated claim in the real estate industry is that overbuilding in the real estate industry is due to irrational developers. Grenadier (1996) has suggested a rational basis for the bursts of construction that sometimes occur just as market prices begin to fall-strategic behavior by competing developers in imperfectly competitive markets. We find some evidence in favor of the Grenadier model; holding the level of prices constant, builders appear more likely to build when prices begin to fall.

More compelling, however, is the observation that the volatility of returns, exposure to market risk, and competition play important roles in the timing of investment. Builders are especially susceptible to business cycle shocks, as developer bankruptcies rise considerably in recessions. If competition is less pronounced in recessions, real options behavior may lead developers to delay irreversible investments in structures longer than they would in booms when markets are more competitive. Given that changes in investment are an important component in the business cycle, these results suggest that uncertainty and competition may play a role in understanding cyclical movements in investment in real estate and the macro economy. 


\section{BIBLIOGRAPHY}

Abel, A.B. Optimal Investment Under Uncertainty. American Economic Review. 73, 1983, 228-33.

Abel, A, A. Dixit, J.C. Eberly, and R. Pindyck. Options, The Value of Capital, and Investment. Quarterly Journal of Economics. 111, 1996, 753-77.

Abel, A.B. and J.C. Eberly. The Effects of Irreversibility and Uncertainty on Capital Accumulation. Journal of Monetary Economics. 44, 1999, 339-77.

Andersen, T. G., T. Bollerslev and F.X. Diebold. Parametric and Nonparametric Volatility Measurement. NBER technical working paper \# 279, 2002.

Bar-Ilan, A., Strange, W., 1996. Urban Development with Lags. Journal of Urban Economics 39 (1), 87-113.

Basu, S. and A.M. Taylor. Business Cycles in International Historic Perspective. Journal of Economic Perspectives. 13 (2), 1999, 45-68.

Bell, G.K. and J.M. Campa. Irreversible Investments and Volatile Markets: a Study of the Chemical Processing Industry. Review of Economics and Statistics. 1997, 79-87.

Bernanke, B.S. Irreversibility, Uncertainty, and Cyclical Investment. Quarterly Journal of Economics. 98, 1983, 85-106.

Black, F. and M. Scholes. The Pricing of Options and Corporate Liabilities. Journal of Political Economy. 81(3), 1973, 637-54.

Bollerslev, T., R. Y. Chou and K.F. Kroner. ARCH Modeling in Finance: A Review of the Theory and Empirical Evidence. Journal of Econometrics. 52, 1992, 5-59.

Brennan, M.J. and E.S. Schwartz. Evaluating Natural Resource Investment. Journal of Business. 58 (Jan.), 1985. 135-157.

Brennan, M. J. and L. Trigeorgis. Project Flexibility, Agency, and Competition: New Developments in the Theory and Applications of Real Options. New York, Oxford University Press, 2000.

Bulan, Laarni T. Real Options, Irreversible Investment and Firm Uncertainty: New Evidence from U.S. Firms. Review of Financial Economics. 14, 2005, 255-279.

Caballero, R. J. On the Sign of the Investment-Uncertainty Relationship. American Economic Review. 81(1), 1991, 279-288. 
Caballero, R.J. and R.S. Pindyck. "Uncertainty, Investment and Industry Evolution." International Economic Review. 37 (3), 1996, 641-62.

Case, Karl E. and Robert J. Shiller. "The Efficiency of the Market for Single Family Homes." American Economic Review, vol. 79, no. 1, 1989, pp. 125-37.

Cleveland, W.S. and S.J. Devlin. Locally Weighted Regression: An Approach to Regression Analysis by Local Fitting. Journal of the American Statistical Association, 83, 1988, 596-610.

DiPasquale, D. and W.C. Wheaton. Housing Market Dynamics and the Future of Housing Prices. Journal of Urban Economics. 35, 1994, 1-28.

Dixit, A.K. Entry and Exit Decisions Under Uncertainty. Journal of Political Economy. 97, 1989, 620-38.

Dixit, A.K. and R.S. Pindyck. Investment Under Uncertainty. Princeton, NJ: Princeton University Press, 1994.

Downing, Chris and Nancy Wallace. A Real Options Approach to Housing Investment. University of California, Berkeley working paper, March, 2001.

Grenadier, S.R. The Strategic Exercise of Options: Development Cascades and Overbuilding in Real Estate Markets. Journal of Finance. Vol. 51 (5). p 1653-79. December 1996.

. Option Exercise Games: An Application to the Equilibrium Investment Strategies of Firms. Review of Financial Studies. 15, 2002, 691-721.

Gutierrez, Roberto G. Parametric frailty and shared frailty survival models. The Stata Journal. 2(1), 2002, 22-44.

Hamilton, S.W. Condominiums: a Decade of Experience in B.C. Vancouver: The British Columbia Real Estate Association, 1978.

Heston, S.L. A Closed-Form Solution for Options with Stochastic Volatility with Applications to Bond and Currency Options. Review of Financial Studies. 6, 1993, 327-343.

Heston, S.L. and S. Nandi. A Closed-Form GARCH Option Valuation Mode. Review of Financial Studies. 13, 2000, 585-625.

Holland, A.S., Ott, S.H., and T.J. Riddiough. The Role of Uncertainty in Investment: An Examination of Competing Investment Models Using Commercial Real Estate Data. Real Estate Economics. 28 (Spring), 2000, 33-64.

Hurn, A.S. and R.E. Wright. Geology of Economics? Testing Models of Irreversible Investment Using North Sea Oil Data. The Economic Journal. 104 (March), 1994, 363-371. 
Kulatilaka, N. and E.C. Perotti. Strategic Growth Options. Management Science. 44(8), 1998, 1021-1031.

Lander, D.M. and G.E. Pinches. Challenges to Practical Implementations Modeling and Valuing Real Options. The Quarterly Review of Economics and Finance. 38 (0), 1998, 537-567.

Leahy, J.V. Investment in Competitive Equilibrium: The Optimality of Myopic Behavior. Quarterly Journal of Economics. 108, 1993, 1105-1133.

and T.M. Whited. 1996. The Effect of Uncertainty on Investment: Some Stylized Facts. Journal of Money, Credit, and Banking 28: 64-83.

Lo, A.W. and J. Wang. Implementing Options Pricing Models When Asset Returns Are Predictable. Journal of Finance. 50, 1995, 87-129.

Majd, S. and R. Pindyck. Time to Build, Option Value, and Investment Decisions. Journal of Financial Economics. 18, 1987,

Mayer, C. and C.T. Somerville. Residential Construction: Using the Urban Growth Model to Estimate Housing Supply. Journal of Urban Economics. 48, 2000, 85-109.

McDonald, R. and D. Siegel. The Value of Waiting to Invest. Quarterly Journal of Economics. 101 (Nov.) 1986, 707-727.

Meese, Richard and Nancy Wallace. Testing the Present Value Relation for Housing Prices: Should I Leave My House in San Francisco? Journal of Urban Economics. 35(3), 1993, 245-66.

Miltersen, K. R. Valuation of Natural Resource Investments with Stochastic Convenience Yields and Interest Rates. in Brennan, M. J. and L. Trigeorgis (eds). Project Flexibility, Agency, and Competition: New Development in the Theory and Application of Real Options. New York: Oxford University Press. 2000.

Moel, Alberto and Peter Tufano. When Are Real Options Exercised? An Empirical Study of Mine Closings. Review of Financial Studies. 15(1), 2002, 35-64.

Novy-Marx, Robert. An Equilibrium Model of Investment Under Uncertainty. University of Chicago working paper, 2005.

Paddock, J.L., Siegel, D.R., and J.L. Smith. Option Valuation of Claims on Real Assets: The Case of Offshore Petroleum Leases. Quarterly Journal of Economics. 103 (August), 1988, 755-784.

Pakes, Ariel. Patents as Options: Some Estimates of the Value of Holding European Patent Stocks. Econometrica. 54 (July), 1986, 755-784. 
Pindyck, R.S. Irreversible Investment, Capacity Choice and the Value of the Firm. American Economic Review. 78, 1988, 969-85.

Pindyck R.S. and A. Solimano. Economic Instability and Aggregate Investment. NBER Macroeconomics Annual. 8, 1993, 259-303.

Quigg, L. Empirical Testing of Real Option Pricing Models. Journal of Finance 48, 1993, 621-640.

Quigley, John and Chris Redfearn. Housing Market Efficiency and the Opportunities For Excess Returns. University of California, Berkeley mimeo, November, 1999.

Rotemberg, Julio and Garth Saloner. A Super-Game Theoretic Model of Business Cycles and Price Wars During Booms. American Economic Review. 76(3), 1986, 390-407.

Rotemberg, Julio and Michael Woodford. Markups and the Business Cycle. NBER Macroeconomics Annual. 6, 1991, 63-129.

. Oligopolistic Pricing and the Effects of Aggregated Demand on Economic Activity. Journal of Political Economy. 1992, 100(6), 1153-207.

Schwartz, E.S. The Stochastic Behavior of Commodity Prices: Implications for Valuation and Hedging. The Journal of Finance. LII (July), 1997, 923-73.

Shiller, R.J. Arithmetic Repeat Sales Price Estimators. Journal of Urban Economics 1 (1), 1991, 110-126.

Sing, T.F. and K. Patel. Evidence of irreversibility in the UK property market. Quarterly Review of Economics and Finance. 41 (3), 2001, 313-334.

Sivitanidou, R. and P. Sivitanides. Does the Theory of Irreversible Investments Help Explain Movements in Office-Commercial Real Estate. RealEstate Economics. 28(4), 2000, 623-662.

Somerville, C.T. Residential Construction Costs and the Supply of New Housing: Finding Consistent Effects of Structure Costs on Homebuilding Activity. Journal of Real Estate Finance and Economics, 18 (1), 1999, 43-62.

Permits, Starts, and Completions: Structural Relationships vs Real Options. Real Estate Economics. 29 (1), 2001.

Thibodeau, T. Introduction to Special Issue on House Price Indices. Journal of Real Estate Finance and Economics 14 (1/2), 1997, 5-11. 
Titman, S. Urban Land Prices Under Uncertainty. American Economic Review 65, 1985, 505-14.

Trigeorgis, L. Real Options. Cambridge, MA: MIT Press, 1996.

Williams, J.T. Real Estate Development as an Option. Journal of Real Estate Finance and Economics 4, 1991, 191-208.

Equilibrium and Options on Real Assets. Review of Financial Studies. 6, 1993, 825-850.

Zanowitz, V. Theory and History Behind Business Cycles: Are the 1990s the Onset of a Golden Age? Journal of Economic Perspectives. 13 (2), 1999, 69-90. 